\title{
The Impacts of Politics and Ethnicity on Volunteering
}

\section{Alexandrea Picken and Simon Lewis}

\begin{abstract}
This article examines how national and local ethno-politics impact on volunteering by taking a cross-country comparative perspective: Kenya and Mozambique. In both countries societal fragmentation along ethno-political lines is mirrored within the volunteer landscape and reduces the positive impacts of volunteering. The role of international volunteers (IVs) from the global North and, in the case of Kenya, national volunteers (NVs), to address these divisions is discussed. The effects of the support of the volunteering for development sector in such ethnically and politically fragmented contexts is also explored. The findings from the current research show that the perceived neutrality of the IV and NV means they may face less risk in attempting to step outside of existing political and ethnic confines than local volunteers or citizens functioning within these environments. Through this neutrality, IVs and NVs may be provided with a unique opportunity to use this position to assuage some of these societal fractions.
\end{abstract}

\section{Introduction}

Politics and ethnicity play an important role in the capacity of volunteering to contribute to development. This article examines how national and local ethno-politics impact on volunteering by taking a cross-country comparative perspective: Kenya and Mozambique. Specifically, we focus on the role of international volunteers (IVs) from the global North and additionally, in the case of Kenya, national volunteers (NVs). In both Kenya and Mozambique the societal fragmentation along ethno-political lines is mirrored within the volunteer landscape and reduces the positive impacts of volunteering. Specifically, the overt influence of party politics in Mozambique means that local volunteers and local and national volunteering interventions are allocated and accessed through political patronage networks and the blurred line between political and civil society space. In this process, volunteering organisations and groups become politicised extensions of the state. In Kenya, 'politicised tribalism' has had a subtle yet profound impact on volunteerism (Lonsdale 2008) wherein local volunteering activities and opportunities take on a tribal twist which deeply affects local trust and social capital.

Despite these difficulties, the Valuing Volunteering research corroborates Lough and Matthew's (2013) proposition that ' $\Pi[$ nternational volunteers are also typically viewed as more neutral and impartial than local actors, which strengthens claims on fairness' (Lough and Mati 2012: 20, cited in Lough and Matthew 2013). Due to IVs' position as 'outsiders', they are often perceived as neutral and more trustworthy. Yet it is also true, as will be shown through research undertaken in Kenya, that 'volunteers from within the region with a high degree of neutrality may be preferable to international volunteers in service as mediators' (Lough 2012: 5). The findings from the current research will show that an IV and NV with perceived neutrality may face less risk in attempting to step outside of existing political and ethnic confines than local volunteers or citizens functioning within the prevailing political and ethno-political norms. Through this neutrality, IVs and neutral NVs may be provided with a unique opportunity to use this position to assuage some of these societal fractions. we differentiate between NVs who are attached to more formal national volunteering schemes or programmes, and local or community volunteers who can be more informal and localised.

This article begins by laying out the political and ethno-political contexts in both countries and the divisions and inequalities these create in civil society. Through case studies in Mozambique and Kenya, discussion will turn to how these divisions are perpetuated in one particular type of civil 
society space: volunteer civil society groups and organisations. We will highlight the conflict that can arise and the impacts this can have on the effectiveness of volunteerism and trust between volunteers and the communities where they are active. The role the international volunteering organisation plays in supporting or challenging such divisions will also be touched upon. We will see that if the volunteering for development sector continues to treat volunteers, volunteer civil society organisations and groups as politically neutral they will at least, fail to challenge the inequalities the ethno-political hegemony creates there, and at worst will support the perpetuation of these inequalities.

\section{Methodological approach}

In both countries there were two main research approaches taken: systemic action research (SAR) and participatory systemic inquiry (PSI). SAR is an action research methodology which is underpinned by an iterative learning process which embeds design, planning, action and evaluation into a single process (12-24 months). Action research is underpinned by the idea that we learn as much from action as from analysis, and that iterative cycles of action and analysis allow rapid learning and the consequent generation of effective adaptive strategies. PSI is a shorter process, which allows a system to be mapped as a baseline against which changes in the dynamics of the system can be assessed (Burns 2012). PSI can underpin an action research process or it can be carried out as a process in its own right.

\section{Both SAR and PSI are meta methodologies, which} can contain many methods. Some of the methods used during inquiries in Mozambique and Kenya include the generation and processing of systems maps; rich pictures; monitoring of workload patterns; surveys; participatory mappings such as Venn diagrams, social networks, resource mapping, force field analysis, community and wellbeing mapping, sustainability matrices; story collection and analysis (Maxson 2012), immersions, observation and transect walks; participatory photography and video; open discussions; semi-structured and unstructured interviews and dialogues. All of these and more were used to explore and deepen the key threads of inquiry that emerged from the wider complex systemic map of the volunteering landscape in each of the countries.

In Mozambique, two main volunteer systems are focal to this article: a small group of 30 local volunteers (although different members of the group had differing levels of involvement in the research); and interviews with the IVs involved in the initiative and informal discussions with several of the staff from the supporting IV organisation. The examples drawn upon come from the National Volunteer Council and a community-led volunteer initiative, Communities Building Futures (CBF), supported by international donors and administered through an international volunteer organisation.

Initially, an SAR approach was taken and a period of community inquiry was undertaken by IV researchers from three of the Valuing Volunteering countries and a systemic map was produced that highlighted the key emergent findings relating to volunteering. Thereafter, a PSI approach was adopted to explore further the concepts emerging from the map. Participatory workshops and focused group discussions were carried out with the local volunteers involved in the initiative.

\section{The Conselho Nacional do Voluntariado (CNV)} or National Volunteering Council investigation focused on a series of structured and semi-structured interviews with key NV stakeholders, and also included observations during national meetings and events (such as the election process). Semi-structured interviews and some participatory activities were undertaken with individuals and small groups from volunteering organisations who consider themselves members of GNV.

In Kenya, research was based around three lead SAR investigations that ran in parallel; they included an inquiry into community volunteering in Korogocho in Nairobi, a comparison of volunteering in three communities in Mombasa and research into the UK government-funded International Citizen Service (ICS) in the coastal community of Kilifi. In each case, a team of local volunteer researchers was trained in participatory methodologies (in Kilifi the team comprised UK and Kenyan volunteers taking part in ICS) to lead and steer the research according to emergent locally significant issues. Each research team was guided through a process of critical reflection or what Freire (1970) terms 'conscientisation' whereby successive cycles of action and reflection were used to challenge and further understanding surrounding volunteerism and its impact on local development.

In addition, six shorter PSIs were undertaken at research sites which included Wundanyi in the Taita Hills of southern Kenya, Nanyuki and Laikipia in central Kenya and Migori in western Kenya. These inquiries typically entailed three 
to ten days of fieldwork during which local volunteers and residents were engaged to map out their development challenges and reflect on volunteerism's past, present and potential role in addressing them. Local and national volunteers were also interviewed and asked to reflect on their volunteer journeys using tools such as rivers of experience (VSO 2004).

A national reference group was utilised as an avenue for disseminating and testing research findings. This reference group comprised representatives of major volunteering for development organisations operating in Kenya.

In both countries, SAR and PSI inquiry findings were validated extensively by repeatedly testing emerging insights with multiple stakeholders. In community settings this included sessions with different types of volunteers, village elders, the local administration such as the village chief, religious and faith leaders, business and landowners and randomised selections of local residents. These groups were also sometimes deliberately mixed to test the applicability of particular findings to specific demographics. A range of participatory methods was used to aid triangulation. The strength of these approaches is that they are built on community narratives and thus enable detailed pictures to be built of how and why things happen, and participatory methods also facilitate in surfacing causal relationships.

Lead researchers were immersed within the volunteer context of their respective countries for a two-year period. This facilitated the development of close working relationships between the lead researchers and the local volunteers. It also allowed the lead researchers to become fully immersed in the specific sociopolitical and economic systems in which volunteering was taking place. This ultimately contributed to a richer and more in-depth understanding of the different volunteer contexts in which they were engaging and inquiring.

\section{Mozambique}

The political context in Mozambique had a strong impact on volunteering. While there have been democratic elections since 1994, there has been distinct polarisation in the candidature by the two largest parties: RENAMO, the Mozambican National Resistance (Resistência Nacional Moçambicana) and FRELIMO, the Mozambican Liberation Front (Frente de Libertação de Moçambique). In reality, 'FRELIMO has gradually expanded its domination and political hegemony' (AfriMAP and OSISA 2009: 10) and has been the only party in power since elections began. Alongside this there is tenuous separation between state and party and FRELIMO functions 'as a political organization that effectively controls the state' (Sumich 2010: 682). This lack of separation gives the party increased power and control over access to resources.

Further, FRELIMO manages to maintain wealth and power through a variety of means:

1 It has dominated access to international donors and networks (Sumich 2010) and similarly in the private sector; and

2 Government party trust-based appointments of managers of public companies increases the party's access to public resources for political/ electoral activity (AfriMAP and OSISA 2009), resulting in a strengthening of the party whereby it channels '... demands and interests internally and impos[es] constraints on the ability of actors to operate independently of its structures' (Sumich 2010: 680).

This situation has led to a lack of access to opportunity and resources for those outside of the party, with advancement being dependent upon demonstrations of loyalty to the party (ibid.). FRELIMO's control extends to civil society spaces, leading to 'Civil Society Organisations (CSOs) being dependent on alignment to the governing party's economic elite, or access to donor funds' (DFID et al. 2008: viii) undermining civil society voice and government's accountability to it. This blurred separation between civil and political spaces undermines CSO autonomy whereby 'political parties [begin] making use of civil society organisations to advance their political interests' (AfriMAP and OSISA 2009: 68).

The overarching formal volunteer backdrop in Mozambique is the purview of the Ministry of Youth and Sport. It holds responsibility for the design, legalisation and implementation of nationwide volunteering, which is perceived to contribute to the achievement of certain 'strategic development areas' related to youth cooperation and solidarity; there is a commitment to 'stimulate the training in and promotion of volunteering in strategic development areas' (Politica da Juventude 2013). The GNV is the main volunteer body through which the government is attempting to fulfil these responsibilities to volunteerism. 


\section{The National Volunteering Council (CNV)}

'Volunteers do represent civil society so this is why the government want to control them. When volunteering is well managed and organised it is good for development. When it is more organised it has more impact. The problem is that when it is organised the government want to control it.' Ex-CNV presidential candidate ${ }^{1}$

The above quote is best illustrated through the example of the GNV, which is responsible for unifying and coordinating national volunteering. It was created in 2001 as a committee through a joint proposal from the Ministry of Youth and Sport and United Nations Volunteers (UNV), to organise an event around the National Year of Volunteers. Initially, there was a ministry-appointed committee leadership structure but in 2008, the first general assembly elections were held, reflecting the intention to shift from a government-directed entity, to a democratic council reflective of volunteering as a role for civil society.

GNV is an umbrella organisation with a remit to promote, organise and capacity build national volunteering; to promote volunteer laws, strengthen networks and exchange information between different CSOs and youths. In theory, GNV and ministry representatives agree the importance of maintaining the council's political autonomy: '... keep the funding of CNV separate from government as it is important that the organisation not be seen as political...' (national volunteering expert) ${ }^{2}$ and '.... $\mathrm{CNV}$, it is the civil society, the government does not make orders in the civil society' (ministry representative). ${ }^{3}$ In practice, CNV's potential power as a collective civil society platform to challenge or strengthen prevailing political authority means that it is appealing to those with political interests to use 'as a tool to connect CSOs for the promotion or dissuasion of the ruling party line' (national volunteering expert), ${ }^{4}$ and for its strategic position - 'If organisations are not co-ordinated under CNV then they are not part of a system which can call upon government for action. CNV ... is like the spokes-body between volunteers and the government' (national volunteer logistics manager). ${ }^{5}$

\section{The battle for presidency of CNV highlights the} point at which the political neutrality of CNV becomes questionable. The following statement from a previous presidential candidate introduces this succinctly: 'I agree that it is a platform for civil society to talk to government and in my opinion this is why there is such control over it by FRELIMO'. ${ }^{6}$ The permeation of the party apparatus into this volunteering CSO is clear when we consider the council's presidential election assemblies. During the research there was a long period of leadership instability, voting and re-voting based on political affiliations of presidential candidates:

\section{$C N V$ is linked to the youth assembly which is part of FRELIMO. The new president that is getting voted in... he is a member of a new political party, MDM [Movimento Democrático de Moçambique]. The youth assembly which is part of FRELIMO are trying to stop him from working and keep calling for a new assembly... There have been two assemblies so far and they are calling for a third. At both assemblies the vote has gone against the current FRELIMO party politics (national volunteer representative). ${ }^{7}$}

The leadership has now stabilised and the MDM sympathising candidate was unsuccessful. CNV's leadership tensions are reflective of the difficult wider societal relationship between civil society and the state. As a result, at the time of writing, CNV was left effectively stagnant as a unifying and strengthening entity for national volunteering and its power as the interlocutor between civil society and government was severely diluted. Local level volunteer civil society groups also exhibit similar political influences.

\section{Communities Building Futures (CBF)}

The internationally donor-funded Communities Building Futures (CBF) initiative was administered through an international volunteering organisation and aimed at supporting locally led, participatory community development through the promotion of volunteer participation and livelihood/income generation activities. After the formation of the community volunteer group, (discussed in detail below) members generated five project proposals. The projects were mostly based around existing skills: chicken rearing, brick, furniture and carpet making and a nursery. The idea was to implement their projects and share their skills with other community members. The volunteers would then create small income generation businesses to provide livelihood support and meet running costs. These would be run by the community volunteers and other community members to whom they taught their skills. The international volunteer development organisation involved would provide support with any training requirements and start-up capital that might be needed for these projects.

In order to understand how wider existing political dominance affects this local volunteering initiative, 
District government

Administrative post

\section{Secretario do Bairro (SDB) (neighbourhood secretary)}

Chefe De Quarterao (CDQ) (Boss of the Block)

Chefe de 10 Casas (CDC) (Boss of 10 Houses)

it is necessary to understand how prevailing party politics reaches down to the local level.

The box above depicts the basic local governance structure in Mozambique. The bold text highlights the secretario do bairro (the neighbourhood secretary, $\mathrm{SDB})$. He is an elected local level authority but often a member or sympathiser of FRELIMO in party sympathetic neighbourhoods. The SDB is the focal point for authorisation and information regarding all activities occurring in the neighbourhood.

Information about what is happening at the household and neighbourhood level will always pass through the SDB and be relayed to the structures further up the administrative hierarchy. There is usually a leader for every ten houses (CDC) who will report to the leader of the block (CDQ) who in turn feeds all information about the neighbourhood to the SDB. When volunteers wish to undertake an activity or have an idea for an intervention within their community they must usually go through these structures to seek the permission of the SDB.

Key actors in this local governance structure have significant influence over access to volunteer opportunities and rewards. These opportunities are attractive as they may bring training, stipends and other resources (although this is not standardised). As well as promoting self-directed, communityowned development, the CBF initiative also involves sharing skills with other community members and access to start-up capital and support to begin small income generation projects and is thus an attractive opportunity.

The SDB plays a pivotal role in the $\mathrm{CBF}$ initiative as community members point out: the SDB 'rules the population of the neighbourhood' (community volunteer $),{ }^{8}$ and was responsible for selecting local volunteers to participate in the initiative. Initially the international volunteer organisation approached the community to generate interest from community members to volunteer but, 'The secretario do bairro says no, we have an organisation here that is doing work here and it has lot of people inside' (community volunteer), ${ }^{9}$ so instead of self-forming to address community needs an existing community organisation was selected to implement the initiative.
After appointment of the local volunteer organisation, volunteer numbers were augmented in order to meet a target number of volunteer hours set by the project. The SDB selected these volunteers through local governance network connections. These volunteers were 'the leaders that the secretary of the neighbourhood sent to participate' (community volunteer) ${ }^{10}$ and 'The leaders came to work as volunteers but in our capacity as bosses, we have some who are bosses of the block but are also volunteers' (community volunteer). ${ }^{11}$

While this process of selection may be positive since 'the secretary of the neighbourhood knows that these people have experience' (community volunteer $)^{12}$ and therefore they hold a degree of credibility in the community which will help to propel activities or mobilise people, it means that those not linked in to the politicised governance network may not be afforded the same opportunity to access the benefits of the volunteer initiative. It is also important to highlight that while access favours FRELIMO supporters it is not limited to them (nonaffiliated volunteers participated in the initiative too).

The SDB motivation for suggesting the local volunteer implementing organisation may have been the organisation's prominence and formalised status in the community, but there is some strong anecdotal evidence that the leadership of the organisation may have political ties: key stakeholders expressed on several occasions that the president of the organisation was a chief mobiliser for the FRELIMO party and was often absent during the busy party campaign period when his mobilising skills would be needed most to organise campaignrelated activities, and key members of the volunteer organisation's leadership were seen undertaking political campaigning in the streets during the election period. While this is not definitive evidence it hints at the political ties that the leadership of the organisation might have. The issue is not about participation of only politically neutral volunteers, yet the apparent distribution of opportunity through party lines is problematic. The five volunteer project ideas may have been generated through a collaborative process by the community volunteers 
(politically affiliated or not), but the biased selection process reduces the potential for a more organic self-forming participatory ethos and reinforces a local volunteering situation mirroring wider societal inequalities in resource access.

The effects of this on volunteering are stark. In particular, the politicisation of volunteer activities and the utilisation of volunteering resources to advance political motives was observed. The leadership is 'very much tied to the political structure and then what they were doing was using the project activities... to tell the rest of the community... that's brought to you by FRELIMO - so there was a direct tie' (international volunteer). ${ }^{13}$ This emphasises how support from international volunteering organisations can inadvertently create a space within which party power and control over resources is strengthened. Thus, when partnering with local volunteering CSOs or groups favouring members of specific political inclinations, international donors/ non-governmental organisations (NGOs) may be unconsciously propagating these societal divisions.

Another impact of politics on this local volunteer group is a lack of accountability. Within the initiative the leadership (primarily three community volunteers) of the local volunteer organisation took financial control, dominating access to financial information, resources and the sole bank account holding the profits and capital for the income generation projects. They were not transparent about financial movements linked to the initiative and concerns about financial mismanagement and corruption were expressed. For example, as one stakeholder recounts:

\section{It's like with the chickens, like paying for 1,000 chickens and then only ever seeing 250 but the money was all distributed for that and it was reported that all those chickens were purchased but, the community never ever saw those and then when those chickens got sold that money never ever made it back into the community (international volunteer). ${ }^{14}$}

This implied that it stayed with the leadership. A community volunteer described

\footnotetext{
the war that exists now it is of corruption, the volunteers are producing. The war that exists just now, we want to open the bank accounts of each sector that is producing... So for us we see that they [the leadership group] have interest and these interests are not for all the volunteers... (community volunteer). ${ }^{15}$
}

A chronic lack of accountability of the volunteer leadership core to the other volunteers gave rise to the 'war' and is reflective of a systemic problem in Mozambique whereby accountability for those showing patronage to the party is low. For example, 'Mozambique remains one of the most corrupt.... countries in the world, with a rank of 120 in transparency' (Faehndrich and Nhantumbo 2013: 11), and while stronger democratic processes and political will help to reduce corruption (Lederman, Loayza and Soares 2001 cited in Ongus 2004: 336), these are strongly lacking in Mozambique.

\section{The potential for corruption within the current} political context is high. While it is true that financial mismanagement could occur irrespective of political affiliation, in a corrupt context with questionable democratic process and lack of political will to change such a system, it is logical to assume that those within political patronage streams, such as the local volunteer leadership core, might escape systems of accountability and transparency.

The effect of this financial mismanagement by the leadership was internal conflict or 'war' within the local volunteer group creating internal conflict between the leadership core and the other community volunteers and an erosion of trust between the volunteers. One of the local volunteers intimated how the usual community accountability mechanisms failed: when the SDB was called upon to help he was not able/willing to challenge the leadership due to their political connections. While the SDB is a key local gatekeeper, he is also caught between bottom-up community-driven concerns and top-down, party mechanisms and thus his capacity to enforce accountability and transparency for local volunteering activities becomes diluted.

The politicisation of volunteering activities and the lack of accountability of volunteers that are affiliated to party political structures causes conflict, division and reduces the effectiveness of the volunteer groups and organisations. The issue is not about depoliticising volunteers or only volunteering if there is a demonstration of political neutrality, the problem arises when those volunteer spaces, human resources and hours are potentially utilised to promote political advancement without being transparent. The result is the perpetuation of political hegemony and the blurred relationship between state and civil society played out within volunteer CSOs and groups, unintentionally supported by international donor funding. This creates an erosion of trust and collaborative activities between community members involved in volunteering. 
A wealth of literature exists on the relationship between state and civil society and difficulties arising due to state over-involvement within these spaces. However, there appears to be a dearth of literature in relation to this relationship within volunteer-specific civil society spaces (such as CBF and CNV). Lough and Matthew (2013) have written extensively on the ways that both NVs and IVs attempt to contribute to good governance in contexts similar to Mozambique, citing the ways in which they can contribute to increasing accountability, transparency, voice and peace (in the case of conflict situations). Some of their observations mirror the current finding regarding the ways in which volunteers facilitate better governance, yet more investigation into how this applies to volunteer civil society groups and organisations within similar political contexts is necessary.

\section{Kenya}

In Kenya, the research found that the ethnopoliticisation of society has had a substantial impact on the volunteering landscape. Whereas in Mozambique volunteering opportunities are controlled by the indistinguishable apparatus of political party and state, in Kenya the fragmentation of society along tribal lines had led to the more subtle entrenching of volunteering activities and opportunities in line with those ethnic divisions.

Kenya has over 40 different tribes, with the Kikuyu, Luhya, Luo, Kalenjin and Kamba representing the largest groupings, which together make up over 70 per cent of the population (Government of Kenya 2013; CIA World Factbook 2015). Despite a wave of nationalistic fervour following independence from British colonial rule in 1963, Kenya quickly 'embraced extreme tribalistic politics' (Prunier 2008) whereby members of the ruling tribe were promoted to positions of power. The old colonial legacy of administrative divide and rule simply evolved into a 'balkanisation [of] coterminous administrative and ethnic units' (Oucho 2002: xvi). The control of state power in Kenya has thus become one of tribal rivalry or what Klopp refers to as the 'unprincipled and divisive competition for state power by members of the political class who claim to speak for unified ethnic communities' (2002: 269). Such rivalry and tensions were most visible in the aftermath of the disputed general election in December 2007 when the violence claimed over 1,200 lives and displaced in excess of 600,000 people (IRIN 2015).

Kenya's 'politicised tribalism' has had a subtle yet profound impact on volunteerism in two distinct ways (Lonsdale 2008). Firstly, echoing fragmentations in society, volunteering activities and opportunities in some cases have taken on a noticeable tribal twist.

For example, in-depth fieldwork in Korogocho - an informal settlement in northeast Nairobi - found that various volunteering activities and initiatives often became segregated along ethnic lines. This applied as much to the volunteering within community-based organisations (CBOs) that tended to be dominated by members of a particular tribe as to the volunteering projects funded by international non-governmental organisations (INGOs). In cases of the latter, in parallel with Mozambique, examples were uncovered where international development organisations would unwittingly partner with local organisations that favoured specific tribes. Within communities struggling with social cohesion across tribal lines, such activities were often taken as tacit support for one tribe over another and ultimately a challenge that many development organisations sought to tackle was made worse.

In poor and marginalised communities, the research found that volunteerism takes on a power dimension when it is perceived as an opportunity to gain resources - something which occurs more often when development organisations pay allowances or stipends to volunteers. In this case it also adopts a local dimension through competition for livelihood resources. As one local resident from Korogocho observed:

Some organizations have favouritism and tribalism. So it's only people from that ethnic group who compete for those opportunities. Like in the case with [an INGO working in the community] who in most cases only recruit CHWs [community health workers] who are [a specific tribe $]{ }^{16}$

In other cases, research participants noted how serving volunteers would try and ensure that any further volunteering opportunities (particularly if they came with a stipend) went to people within their tribal grouping or family. In places such as Korogocho, volunteerism and the opportunities associated with it (such as the stipends and allowances that INGOs often pay to their volunteers and the prospect of external funding) are thus inherently linked to local power dynamics and the struggle for limited resources.

In such circumstances, it is not surprising that whole organisations emerge as $\mathrm{CBO}$ s with an either explicit or implicit focus on helping specific tribes. 
What was particularly revealing from the research was how some local organisations would pursue this in very subtle ways. Such examples included organisation members not using their surnames which would mean easy identification of their tribe. In one case, following over six months' engagement with one local $\mathrm{CBO}$, an interview with one member uncovered how they felt isolated and marginalised within their organisation because they were of a different tribe to the vast majority of members. Even within the organisation, the member noted how they were rarely informed when volunteering opportunities came up that paid an allowance and such opportunities always went first to members of the dominant tribe. As an interview participant stated, 'you've not seen how they work, who do you think they help first, it is always their tribe'. ${ }^{17}$

The example illustrates how ethnic divisions, although not always explicit, manifest themselves in the practices of some local organisations and the ways in which volunteering opportunities are acquired and echoes findings from Mozambique whereby only those within political networks are able to acquire volunteer opportunities and resources.

The second way in which ethno-political fragmentation and tension has affected volunteerism is through its impact upon local trust and to an extent social capital, taken here as referring to the presence and strength of relations and networks between individuals, families, groups and communities (Putnam 1995; Graham et al. 2013). As a 'people-centred' and 'relationship-based' development approach, volunteerism relies on factors that promote the development of strong and trusting relationships in order to be effective. For example, local CHWs in Kenya reported how it was difficult to go about their duties if the community did not trust them. They therefore had to invest significant time in earning the trust of community members and building relationships with them. However, the research found that ethno-political fragmentation eroded trust between people of different ethnicities which negatively impacted on the ability of volunteers to work across tribal lines.

Social capital also took on a tribal dimension as supporting relationships between people in communities became determined by ethnic affiliation. With people less likely to volunteer for the benefit of people outside of their tribe, volunteerism therefore acts as a mechanism for perpetuating rather than challenging social divides. In poor and marginalised communities it was also observed to undermine the capacity of local people to lead their own development as people preferred to rely on external assistance than risk working together with local people from different tribes. As one research participant from Korogocho stated:

\section{[Ethnicity] is an issue and leads to dependency because} people will not trust each other so everyone wants for themselves and their tribe and their friends and family. So they rely on outside help and wait for a rise in their ethnicity which will bring them benefits. ${ }^{18}$

The side-effects for volunteering are that people are either less likely to want to volunteer or will often prefer to volunteer along tribal lines. For those volunteers in roles working across ethnic groups, the lack of trust creates a disabling environment to building the kind of relationships that they need to effectively undertake their activities. As a result, volunteers noted having to invest significant time into slowly building relationships. While this was not seen as a 'quick fix', the research did find that volunteerism could still make a valuable contribution when such long-term approaches were pursued.

The research in Kenya found that the dynamics of trust created interesting variations in terms of the roles and potential effectiveness of different types of volunteers. For example, in highly divided communities such as Korogocho, community members noted how they are less likely to trust NVs from other parts of Kenya as they did not know if they came with their own agenda. Trust in local community volunteers varied greatly from those seen as 'masquerading to defraud and/or exploit others' (local community respondent $)^{19}$ to more trusted volunteers in formalised schemes such as local CHWs. Still, even CHWs reported how community trust had to be earned and did not necessarily come easily, with one stating that 'sometimes I will not be invited in as they see me as a thief' or will be 'likened to harlots or prostitutes as we go door-todoor introducing ourselves'. ${ }^{20}$

While barriers to the effectiveness of volunteering are created by tribal and political divisions, on the flip side, in both country contexts volunteers played a crucial role in redressing some of these inequalities and negative impacts. As will be explored later in the article, one key to this may be in their unique position as outsiders to political and tribal norms that perpetuate such inequalities, either as international volunteers from the global North or as local volunteers who are perceived to be neutral to existing societal divisions along political or ethno-political lines. 
In the case of Korogocho, when trust is lacking in communities between social groups, IVs have the potential to sidestep local/national ethno-political tensions. In essence, they can use their 'outsider' status and perceived objectivity and independence to better work across tribal divisions (Lough and Matthew 2013: 15). This affords them increased trust from the community where they are working and was repeatedly referred to across community studies in Kenya. In the Korogocho community, one local resident observed how,

\section{if two locals call for a project and then two 'mzungus' [white people] call for a project then people will run to the 'mzungus' because when they say they will do or give something they will... but Kenyans will say and not do, even their elected leaders. ${ }^{21}$}

The perceived detachment and impartiality of IVs from 'politicised tribalism' and inherent corruption make their use a potentially valuable development intervention in fragmented societies. As one local Kenyan volunteer commented,

People have learnt not to trust locals because they believe people from the community, just like our leaders, can just be mischievous and even lie about helping us. However, help from a 'white man' - the community believe - is genuine. ${ }^{22}$

While this may not be true, it is a common perception held by community members and national volunteers which appears to influence the degree of acceptance and trust placed in the IV as compared to the local or NV. In Mozambique, one IV from the global North working on the $\mathrm{CBF}$ project stated that another facet of their role as an 'observing outsider' during the process helped, 'especially as an outsider and being a sort of observer for the first little while, it has to be somebody's place to talk about those things when they are happening...'. The IV continued:

as an outsider, I faced very little repercussion in saying exactly what was going on, I was not scared... I didn't have the fear of other community members and so it was ok for me to be the bad guy. It was ok for me to do that and see things that, or to give a picture that may be the individuals in the community couldn't see or couldn't say, so that was part how I viewed my role (international volunteer). ${ }^{23}$

In support of this idea studies have suggested that the best volunteer mediators come from outside the area of the ethnic or political group and 'may play an impartial role in mediating high conflict situations, and may be more creative and flexible in their approach to solving conflict' (Lough and Mati 2012: 5, cited in Lough and Matthew 2013). This role as an outsider can facilitate the volunteer's ability to catalyse and negotiate some specific processes to help redress the political or ethnic biases experienced when wider societal fractions infiltrate volunteering CSOs, groups and initiatives.

A twist to this 'outsider role' is seen in the case of the Kenyan UNV peace monitors. This volunteer initiative employs a targeted volunteer approach utilising skilled Kenyan national professionals recruited from their local areas to reduce ethnopolitical divides and mediate conflict. They provide expert support to the national infrastructure of peace committees. These operate at multiple tiers from the county to the village level and act as a means of mediating local conflicts. Importantly, success has been underpinned by a clear recognition that a skilled national volunteer with a high degree of perceived neutrality is better suited to assuage societal divisions.

Peace monitor volunteers are selected because of their perceived neutrality in their communities. This can be a sensitive process; where candidates are from a major local tribal group, they need to demonstrate their experience and desire to work across tribal lines. Alternatively, in some cases peace monitors are recruited from smaller tribes that are seen as less embroiled in local power disputes. For the peace monitors it is the combination of local expertise with perceived neutrality that is essential to success. One peace monitor based in west Nairobi reflected:

What I've realised in this big network of peace building is that communities have built confidence in us, the volunteers of peace. So they need us to resolve their issues. When there is a problem, when we come the problem will be resolved, because they tend to feel... we are peace builders, we are neutral, we are very neutral. ${ }^{24}$

In additional to their neutrality, local UNV peace monitor expertise also allows them to navigate local perceptions that may affect their ability to resolve conflicts. Having this insider knowledge about key stakeholder perceptions in their communities allows them to better build relationships between volunteers and other development actors including communities and the local administration. For example, one peace monitor based in Nairobi revealed how being seen as connected to the UN was more of a barrier than a helping factor: 
When you're on your own, you're normally not UN... we don't tell people, we do not wear that badge, because... people in the grassroots communities, they do not differentiate between $U \mathcal{N}$ volunteers and UN. They only see $U \mathcal{N}$ as having a lot of money. Expectations... people may expect a lot from you, people even start asking for motorcycles! So when we are on our own we are just maybe government officials, but volunteers... [and people think] you have a big heart if you're volunteering for the government... it's a perception. ${ }^{25}$

Peace monitors that the research spoke to showed significant skills in navigating varying perceptions in order to effectively carry out their duties well. In this case, local expertise and connectedness to local networks when combined with perceived neutrality has been effective. This supports Lough and Mati's assertion that 'volunteers from within the region with a high degree of neutrality may be preferable to international volunteers in service as mediators' (2012: 5, cited in Lough and Matthew 2013). As such, peace monitors have managed to address ethno-political divisions by acting as 'insider mediators' (Abdi 2009: 1).

Whether international outsiders or national insider mediators, the neutrality that the volunteers bring to the volunteering context can assist the reduction of these divisions in several ways. In both Mozambique and Kenya, one key area of the volunteers' success was creating and opening up new spaces of participation and which can have significant impacts on redressing the balance within volunteering contexts. While most of the views expressed in this section are from the perspective of the IV there is some indication that the local volunteers (especially in the case of Mozambique, discussed below) were capitalising on the 'neutral/ outsider' status of the IV who was instrumental in helping the local volunteers to renegotiate the power imbalance in the initiative.

\section{Filling a governance and accountability void}

Peace committees in these remote areas of Kenya have been a self-generated response to a governance void, caused by a weak state presence, and in part fuelled by sub-national inequalities in Kenya's development. As people increasingly feel they have an avenue to decision-making processes, they become less inclined to use violence and conflict as a means to airing their grievances. Vital to this has been the use of volunteers to support what are inherently locally rooted dispute resolution mechanisms and platforms for building social cohesion. As one peace monitor ${ }^{26}$ reflected, 'the structure has also provided the ownership of the peace work by the community... the conflicts have also been managed by the community themselves'.

Through their support to the peace committee infrastructure, peace monitors have succeeded in creating new spaces and practices of governance and renegotiating relations between the state and communities. These committees are spaces for selfgovernance where the apparatus of the state was either weak or lacking. This has been particularly evident in Kenya's remote northeast, where they have filled 'the security void left by the government in conflict prone areas' (Adan and Pkalya 2006: vi). As one NGO research respondent explained:

You find government institutions within small centres that are far away from the people, [there are] very few towns. The government officials, security organs that are there are few... [and are] either poorly staffed, poorly supplied; so there are bad roads and so on. So when incidents of violence and conflict occur, the government officials actually decide to take cover. ${ }^{27}$

In Mozambique, there is evidence of international volunteers acting as a link to restore financial accountability to the initiative described earlier. While IVs were matched to volunteer roles related to their skills and expertise, the 'informal roles' they adopted, as a key link person between the local disempowered volunteers participating in the initiative and the international volunteering organisation accountability mechanisms, became crucially important. Due to the IVs' position as 'outsider' to the community they could act as a spokesperson (link) to raise awareness of the conflict and financial mismanagement that was going on at community level with the international organisation administering the finances. This linking role allowed the IV to transmit messages coming from the community to those INGO stakeholders in a position to support the reintroduction of transparency and accountability (through requesting financial documentation and accounts and enforcing the opening of individual bank accounts). This effectively contributed to dilution of the power that the leadership had over the initiative and contributed to rebalancing the power in the local volunteer group. The community volunteers directly (often covertly) asked for this help as they did not feel they were in a position to confront the leadership alone and thus were utilising the position of the IV as an outsider to begin to bring some accountability and transparency back to the initiative. 


\section{Creating new spaces for participation}

In Mozambique, the amplification of community volunteer voice towards accountability enforcers was not only facilitated through IVs acting as a communication link, but the latter also helped open up spaces in which community volunteers could explore difficult issues occurring in the community and communicate these concerns to the INGO resourcing the volunteering initiative. Due to the IVs' role as outsider and with closer proximity to the INGO, they were in a position to organise these participatory spaces with little repercussion for themselves and create a safer space for local community volunteers to participate. This took the form of participatory workshops and joint meetings where the volunteers could speak freely away from the power-holding leadership. This provided a platform to begin redressing governance and accountability issues in the community.

In Kenya, a similar volunteer function arises in the form of the peace committees. These have created a new tier of governance based on participation. Where they have been most successful is where they have reached out and amplified the voice of the most marginalised. One monitor described how one of her greatest challenges was in dealing with a particularly violent gang in Nairobi's Kawangware slum. After some time, she was able to engage the ringleaders in dialogue, where they confided that they felt isolated and marginalised from decisionmaking. This was a turning point and they have since become engaged in the process and are now active as local champions of peace. This avenue for linking marginalised groups to decision-making processes is creating a situation whereby 'a hitherto disempowered and voiceless indigenous community now has a voice and participates in some governance processes' (Elly Maloba, UNV peace monitor for Narok North). ${ }^{28}$

The effects reported here are primarily based on the perceptions of IVs' and the researchers' interactions with the community volunteers. However, the process of demanding greater accountability appears to have had significant impact in that, in the case of the community volunteer organisation in Mozambique, when new leadership elections took place, accountability mechanisms were re-established. However, the views of community volunteers regarding this process were difficult to glean, as the researcher was no longer working in the community at this point.

\section{Negotiating entrenched and representative relationships}

Finally, another common finding between the two settings which demonstrates the value of volunteers in addressing general societal divisions and those which infiltrate and manifest within volunteer spaces, is their ability to renegotiate relationships and reinstate good governance.

Peace committees and their supporting UNV peace monitors have negotiated new relationships and governance practices where previous methods have either failed or been ineffective (Abdi 2009). A good example is the traditionally tense relationship between the police and communities. Khadija Hassan, a peace monitor in western Nairobi, noted how one of her biggest successes has been building trust between communities and the police without using force. She describes how 'we became the link between the community and the police' and pioneered the use of alternative dispute resolution mechanisms. With a preference for mediation over arbitration, the peace committees have modelled a new way of resolving conflicts, rebuilt trust between communities and the local administration and fostered dialogue and participation where once there used to be only state command and control (Africa Development Alternatives 2009).

In Maputo the politically linked leadership of CBF initiative was not seen by the other volunteers as representative of their group. The leadership core had been elected as representatives of the preexisting local organisation selected by the SDB. Community volunteers requested of the INGO that they 'come to meet with us in the feeling to create a proper structure for [our volunteer group]... because this structure doesn't exist' and further

we ask for help also for the elaboration of the regulations, that regulate the functions of the volunteers... These documents are very important for the volunteer. These documents will cut the wings of [the leadership core] because the volunteers will have their own legal instrument to do their work. ${ }^{29}$

This request came from a group of community volunteers outside the power core, during a covertly requested meeting with an IV working on the project. As a result of the 'safe space' created to enable these discussions, the local volunteers were able to request new elections and support for the devolution of power and these messages were transferred to the INGO by the IV. The local volunteers could not be seen to ask openly for an 
election themselves, whereby they proposed that the INGO support them to redistribute power, not through announcing a need for an election immediately and outright, because 'it would seem that there is an escape of information' (community volunteer). ${ }^{30}$ They preferred a less risky way to redistribute the power through holding an election about the opening of separate bank accounts for each of the five different projects, stating: ' $\ldots$ this separation of the accounts, that will be opened for the members, this will be a distribution of power' (community volunteer). ${ }^{31}$

The role of the IV was to hold a space for local disempowered volunteers to voice their concerns, answering their need for non-confrontational support to negotiate with community power holders and link it back to the INGO with the power to enforce accountability. In this manner they have the support of 'outsiders' to shift the leadership and control of power of the volunteering civil society group.

The community volunteers actively sought the support of the IV in the hope of reinstating accountability and representative leadership in the local community volunteer group. Further, they carefully advised how the IV should interact with the power holders in the community volunteer group, using the position of the IV to their advantage when they were unable to take on an overtly powerchallenging role themselves.

\section{Conclusions}

From the research in these country contexts, initial findings highlighted the negative impacts of wider systemic political and ethnic divisions in volunteer CSOs, groups and initiatives. These include biased access to volunteer opportunities and resources; volunteers opting to offer help only to those in their own tribal network; stagnant and ineffectual volunteering which is prohibitive to volunteers' capacity to collectively or individually affect change; the perpetuation of corruption and lack of accountability in these volunteer examples and in the worst case the strengthening of biased political and ethnic divisions and practices through the support and creation of volunteer spaces where these tensions infiltrate.

However, the role that IV and NV 'outsiders' can play in negotiating complex power relationships that occur in ethno-politically influenced environments or in volunteer civil society groups where such power dynamics have permeated is apparent. The value of neutral NVs and global North IVs in negotiating more representative relationships and structures and building trust between previously conflicting groups, is a strong emergent research theme. This theme was reinforced by the experiences and perceptions of the IVs but also it is evident that in some cases (the $\mathrm{CBF}$ initiative) local volunteers use the IV to their advantage by calling upon and actively utilising the IV in attempts to renegotiate or reclaim their power.

Further, in Kenya, the research would appear to strengthen the assertion that theory and practice predict that volunteers from outside may make a significant contribution as third-party intermediaries and may work with local actors to pressure decisionmakers to reconsider priorities' (Lough and Matthew 2013: 16) whereby the perceived neutrality of NVs such as the local peace monitors appears to facilitate reinstatement of governance and accountability mechanisms in volunteering organisations, groups and the wider community, through creating increased ownership over platforms for disempowered groups to link with decision-makers.

In Mozambique, IVs provide a communication route for volunteers to link to key INGO stakeholders helping to restore accountability at the community level, also in alignment with Lough and Matthew's (2013: 8) finding: that 'volunteers' connections as independent agents heighten organisational transparency and accountability'. The result being, that the INGO through the IV can begin to rebalance accountability. This stands in contrast to the previous point regarding the INGOs' potential to inadvertently perpetuate political or ethnic divisions through funding local volunteer civil society spaces that manifest these biases, and highlights the importance of volunteer INGOs being well-informed of such societal divisions beforehand in order to maximise their capacity to counter these divisions rather than worsen them.

Another valuable effect of the IV and NV was their ability to amplify the voice of the more marginalised, who were often on the wrong side of the political or ethnic divide. This is crucial to begin to empower local communities through meaningful participation. Yet, there are central factors to consider which influence the ability of the volunteer to engage in these roles; while the position of a neutral outsider helps to transcend the ethnopolitical boundaries experienced by local volunteers and citizens, it places a heavy responsibility on the individual volunteer. Doubtless it requires a politically savvy volunteer with good selfawareness to understand the wider context in which 
volunteering is taking place and their positionality within this. In Kenya, effective international volunteers were essentially seen to merge their 'outsider' status with 'insider' knowledge. The time taken to develop an understanding of the political context is an important consideration for INGOs working through volunteers in such contexts, if they want them to be able to navigate these complex societal dynamics and prevent perpetuation of such. It is not only the neutrality of volunteers that helps to address these divisions, they also need to have the right skill set and approach to interact successfully in such situations. As Lopez Franco and Shahrokh (2012) state, volunteer 'capacity development interventions are constantly perceived as a technical endeavour, avoiding critical reflections on what capacities are required to enable people and organisations to understand and change the dynamics of power that impede social change from happening' (Clarke and Oswald 2010: 1, cited in Lopez Franco and Shahrokh 2012); hence, de-politicising the act of building capacities through volunteering'. There is an important consideration if volunteer-supporting organisations are to begin to create change within such ethno-politically hegemonic contexts.

Whether an IV or an NV in a local context, stakeholders with an interest in volunteering for development must ask themselves how they will begin to weigh up the best combination of volunteers for differing contexts. Perhaps being more strategic about the potential of volunteers to play the 'neutral outsider' role will better enable stakeholders in the volunteering sector to provide a tailored approach to volunteering that can begin to dilute entrenched political and ethnic biases and contribute to more effective volunteering for development. Crucial to this is that volunteer-supporting organisations should consider the degree to which they can prepare volunteers for entering politically or ethnically charged environments. Especially when considering the risk to volunteers who attempt to confront or counteract a dominant hegemony in these situations. If this is to be an explicit role for volunteers it is crucial for the volunteer development sector to begin asking how best to protect and prepare the volunteers (IVs or NVs) for these situations.

When structural issues are recognised and addressed, in the contexts where the IV or NV are active, this may make it easier for communities to utilise the volunteers' skills and experience (Lopez Franco and Shahrokh 2012). We see this in the case of Mozambique: where IVs were able to begin to directly combat some of the effects of this type of politicisation at a localised community level and local community members actively utilised them to help re-establish equality within their group.

The question remains as to the capacity of volunteers to have similar effects in the national volunteer arena (CNV), where the link between powerful overarching political agendas and volunteering is played out more visibly and, where the potential for civil society collective voice to more powerfully challenge the political or ethnic hegemony is present. We must question whether it is realistic and appropriate to expect international or NVs to utilise their outsider role in combating these bigger structural inequalities and ask whether Lough's assertion that individual volunteers have difficulty in undertaking such a task alone (2012) holds true in such ethno-politically divided contexts.

This brings us to question whether the volunteer's position as a neutral outsider aiming to re-establish aspects of good governance might be more effective at the local level. While the Kenyan UNV peace monitor approach and the work of Lough and Matthew (2013) provide good examples of the ways in which volunteers attempt to combat these wider structural issues affecting governance in civil society, the ways in which volunteers attempt to do this in specific volunteer civil society spaces needs more exploration. If the volunteer sector can begin to acknowledge and counter these wider structural political and ethnic divisions, this could go far in ensuring that civil society volunteer spaces remain effective, transparent and free from the permeation of such political and ethnic divisions in society that perpetuate inequality. 


\section{Notes}

1 Interview, Maputo, 2013.

2 Interview, Maputo, 2013.

3 Interview, Maputo, 2014.

4 Interview, Maputo, 2013.

5 Interview, Maputo, 2012.

6 Interview, Maputo, 2013.

7 Interview, Maputo, 2013.

8 Interview, Chamanculo, 2014.

9 Interview, Chamanculo, 2014.

10 Interview, Chamanculo, 2014.

11 Interview, Chamanculo, 2014.

12 Interview, Maputo, 2014.

13 Interview, Maputo, 2014.

14 Interview, Maputo, 2014.

15 Interview, Maputo, 2014.

16 Interview, Korogocho, 9 April 2014.

\section{References}

Abdi, D.I. (2009) Insider Mediators: Exploring Their Key Role in Informal Peace Processes - Insider Mediation in Kenya, Berlin: Berghof Foundation for Peace Support Adan, M. and Pkalya, R. (2006) The Concept Peace Committee: A Snapshot Analysis of the Concept Peace Committee in Relation to Peacebuilding Initiatives in Kenya, Rugby: Practical Action

Africa Development Alternatives (2009) Participatory Project Review: Neighbourhood Volunteer Scheme, Nairobi: Africa Development Alternatives AfriMAP and OSISA (Open Society Initiative for Southern Africa) (2009) Mozambique Democracy and Political Participation: A Review by AfriMAP and The Open Society Initiative for Southern Africa, Johannesburg: Open Society Institute Network

Burns, D. (2012) 'Participatory Systemic Inquiry', IDS Bulletin 43.3: 88-100

CIA World Factbook (2015) Kenya, www.cia.gov/ library/publications/the-world-factbook/geos/ ke.html (accessed 6 June 2015)

DFID, Belgian Development Cooperation, Danida, Federal Ministry for Economic Co-operation and Development, Norad, Sida and SDC (2008) Evaluation Report EV688 Citizens' Voice and Accountability Evaluation, Mozambique Country Case Study, Final Report, London: DFID

Faehndrich, M. and Nhantumbo, I. (2013) Advancing Accountability Through Conselhos Consultivos in Mozambique: PROGOAS Case Study, IDS Working Paper 420, Brighton: IDS

Freire, P. (1970) Pedagogy of the Oppressed, New York NY: Herder and Herder

Government of Kenya (2013) Kenya Population Situation Analysis, Nairobi, Kenya: National
17 Interview, Baba Dogo, Naiorbi, 22 January 2013.

18 Interview, Korogocho chief's camp, 18 February 2014.

19 Focus group response conducted on 8 April 2014, Korogocho chief's camp.

20 Interview, Korogocho, 7 April 2014.

21 Interview, Korogocho, 3 September 2013.

22 Interview, Korogocho, 19 March 2014.

23 Interview, Maputo, 2014.

24 Interview, Nairobi city centre, 28 May 2014.

25 Interview, 10 June 2014.

26 Email questionnaire response, 25 May 2014.

27 Interview, Kilimani, west Nairobi, 29 January 2014.

28 Email questionnaire response, 4 June 2014.

29 Interview, Maputo, 2014.

30 Interview, Maputo, 2014.

31 Interview, Maputo, 2014.

Council for Population and Development (NCPD) and United Nations Population Fund (UNPF) Kenya Country Office

Graham, L.; Patel, L.; Ulriksen, M.; Moodley, J. and Mavungu, E.M. (2013) Volunteering in Africa: An Overview of Volunteer Effort in Africa and its Potential to Contribute to Development, Johannesburg: Centre for Social Development in Africa, University of Johannesburg and the Swedish Red Cross

IRIN (2015) Kenya: No Ordinary Elections, www.irinnews.org/report/97508/kenya-noordinary-elections (accessed 6 June 2015)

Klopp, J.M. (2002) 'Can Moral Ethnicity Trump Political Tribalism? The Struggle for Land and Nation in Kenya', African Studies 61.2: 269-94

Lonsdale, J. (2008) 'Kenya: Ethnicity, Tribe and State', Open Democracy, www.opendemocracy.net/ article/kenya_ethnicity_tribe_and_state (accessed 6 May 2015)

Lopez Franco, E. and Shahrokh, T. (2012) 'Literature Review to Inform the Design of Valuing Volunteering', unpublished, Brighton: IDS

Lough, B. (2012) Participatory Research on the Impact of International Volunteerism in Kenya: Provisional Results, Fitzroy, Australia: International Forum on Development Service

Lough, B. and Matthew, L. (2013) Measuring and Conveying the Added Value of International Volunteering, Forum Discussion Paper, www.france-volontaires. org/IMG/pdf/ivco2013_measuring_and_ conveying_the_added_value_of_international_ volunteering_lough.pdf (accessed 4 August 2015) Maxson, M. (2012) The 'Real Book' for Story Evaluation Methods, Global Giving Foundation, http://chewychunks.files.wordpress. 
com/2012/05/storytelling-realbookmay-23-2012.pdf (accessed 7 August 2015)

Ongus, A. (2004) 'Corruption and Regulatory Structures', Law and Policy 26.3 and 4, July and October: 329-46

Oucho, J.O. (2002) Undercurrents of Ethnic Conflicts in Kenya, Boston MA: Brill

Politica da Juventude [National Youth Policy] (2013) Pilar 9, Ponto b, Republica de Moçambique [not yet online]

Putnam, R. (1995) 'Bowling Alone: America's

Declining Social Capital', fournal of Democracy 6.1: 65-78
Prunier, G. (2008) 'Kenya: Roots of the Crisis', Open Democracy, www.opendemocracy.net/article/ democracy_power/kenya_roots_crisis (accessed 6 June 2015)

Sumich, J. (2010) 'The Party and the State: Frelimo and Social Stratification in Post-socialist Mozambique', Development and Change 41.4: 679-98

VSO (2004) Participatory Approaches: A Facilitator's Guide, London: VSO 